\title{
PERFIL DO PACIENTE SUBMETIDO À ENDOSCOPIA DIGESTIVA ALTA DE URGÊNCIA EM HOSPITAL DE REFERÊNCIA EM TERESINA-PI
}

Welligton Ribeiro Figueiredo / Hospital Getulio Vargas; Mayara Magry Andrade da Silva / Hospital Getulio Vargas; Ana Beatriz Silva Lima / UESPI; Ana Clara Alves Ferreira / UESPI; Mychell Holanda Cosme / Uninovafapi; Rafael Felipe Martins de Oliveira Viana / Facid; Amanda Maria Barradas Monteiro de Santana / UESPI.

RESUMO - Contexto - A prática gastroenterológica sofreu uma verdadeira revolução com a introdução da endoscopia digestiva, principalmente a partir da década de 1960, após o desenvolvimento de técnicas e aprimoramento do conhecimento científico. Hoje a endoscopia digestiva alta (EDA) ocupa papel importante no arsenal diagnóstico e terapêutico na prática médica. Objetivo - Caracterizar o perfil do paciente submetido à endoscopia digestiva alta de urgência em um hospital de referência em Teresina-PI e como objetivos específicos determinar os principais sinais e sintomas que levaram ao procedimento de urgência bem como as principais indicações da EDA de urgência, Métodos - Trata-se de uma pesquisa do tipo documental, retrospectiva, caráter descritivo e abordagem quantitativa realizada no Hospital de Urgências de Teresina (HUT). Foram analisados 378 prontuários e fichas de solicitação de exame e extraída uma amostra final de 90 pacientes que foram submetidos à endoscopia digestiva alta de urgência no período de 01 de janeiro de 2013 a 31 de dezembro de 2013 . Resultados - O paciente submetido à EDA de urgência em um serviço de referência em Teresina-PI, em sua maioria, é adulto, do sexo masculino, entre a sexta e metade da sétima década de vida (61 a 75 anos),com média de 54,4 anos de idade. Dentre os sinais e sintomas apresentados inicialmente destacam-se a hematêmese (39\%), dor abdominal (17\%) e melena (12\%). As principais causas de indicação de EDA foram hemorragia digestiva alta, seguida de dor abdominal e anemia a esclarecer. Os diagnósticos pós-EDA mais encontrados foram gastrite, esofagite eou varizes esofágicas que juntos representaram $54 \%$ dos resultados, ressaltando que um paciente pode apresentar mais de um achado diagnóstico durante o exame. Conclusão - A maior parte dos pacientes analisados nesse estudo não necessitou de terapêutica endoscópica. Quando submetidos à EDA, a principal indicação de intervenção foi o tratamento de hemorragia digestiva, sendo a esclerose com adrenalina a modalidade mais realizada ( $57 \%$ dos casos). 